\title{
CAN WORD ASSOCIATIONS AND AFFECT BE USED AS INDICATORS OF DIFFERENTIATION AND CONSOLIDATION IN DECISION MAKING?
}

\author{
Ola Svenson (1) and Paul Slovic (2) \\ (1) Department of Psychology Stockholm University \\ S 10691 Stockholm, Sweden \\ (2) Decision Research Eugene \\ 1201 Oak Street Eugene, Oregon 97401 USA \\ Decision Research Report No. 02-04
}

February, 2002

\section{Footnote}

This study was made possible by grants from The Swedish Research Council and US National Science Foundation. The Royal Netherlands Academy of Arts and Sciences provided a scholarship to the first author enabling him to stay at NIAS to start the project. The authors want to thank Robyn Dawes, Maj-Lene Hedenborg, Cilla Kleerup, C.K. Mertz, Paula Pátkai and Sanny Shamoun for valuable comments on earlier versions of this paper, discussions and assistance. 


\begin{abstract}
Two studies investigated how free associations to decision alternatives could be used to describe decision processes. Choices between San Francisco and San Diego as a vacation city were investigated in the first study with US participants. The participants were asked to list any association that occurred to them while thinking about each of the cities in turn. After this, the attractiveness values of these associations were elicited from each individual. Half of the subjects gave the associations before the decision and half after having made their decisions. In congruence with Differentiation and Consolidation theory (Svenson, 1996), the attractiveness values of the associations were more supportive of the chosen alternative after the decision than before primarily on more important attributes. The results also showed that a significant number of associations were neutral and had no affective positive or negative value. The participants in the second very similar study were also asked to rate their immediate holistic/overall emotional reactions to each of the vacation cities (in this case Paris and Rome with Swedish subjects) before the start of the experiment and the associations. After having given their associations, rated them and made their decisions, the participants were asked to go back to their earlier attractiveness ratings and judge the strengths of the emotional/affect and cognitive/rational value components of each of the earlier associations. The results replicated the results from the first study in that the average rated attractiveness of the associations to a chosen alternative was stronger after a decision than before. However, the change was smaller than in Study 1, which was interpreted as a possible result of the initial holistic associations given in Study 2. It was concluded that the technique of free associations is a valuable tool in process studies of decision making, here based on the Diff Con theoretical framework.
\end{abstract}




\section{Introduction}

Human decision making can be modeled with different purposes. In some cases the prediction of choices is the main goal and in other cases it is the description of the decision processes leading to the choice that is in focus. The present study will focus on the descriptive approach and Differentiation and Consolidation (Diff Con) theory (Svenson, 1992, 1996, 2001). A method usually used in predicting choices, the Word Association and Imagery Decision (WAID) analysis method will be used to explore if it can be used to describe decision processes within the Diff Con framework. The WAID method is supported by the theoretical framework of the affect heuristic, which will be described below (Benthin, Slovic, Moran, Severson, Mertz \& Gerrard, 1995; Slovic, 2001; Slovic, Finucane, Peters \& MacGregor, 2001). As just mentioned, the descriptive perspective is represented by Differentiation and Consolidation (Diff Con) theory (Svenson, 1992) modeling psychological processes before and after a decision. Thus, the present study has the chief purpose of answering the following question. To what extent can free associations and their attractiveness be used as indicators of human decision processes, here modeled in the Diff Con framework? In the following, the affect heuristic will be presented first followed by Diff Con theory. Then, the Word Association and Imagery Decision method (WAID), will follow.

\section{The Affect Heuristic}

Most decisions are made very quickly often without conscious awareness that a decision was made. Some of these decisions are made in a pattern matching kind of process in which a whole decision situation is automatically recognized and linked to a decision response through prior learning. In other situations, quick processes of an affective kind are aroused and the alternatives are automatically linked to positive (approach) or negative (avoid) attractiveness. The affect heuristic was introduced by Slovic and colleagues (Slovic, 2001; Slovic, Finucane, Peters \& MacGregor, 2001) and is related to earlier work in learning theory (e.g., Mowrer, 1960a,b) and work by Damasio (1994) and Epstein (1994).

Affect as used in the context of the affect heuristic means the specific quality of good or bad experienced as a feeling state and the transfer of such a feeling onto a stimulus (alternative) as a quality of the real or imagined stimulus itself. Affective responses to stimuli occur quickly and automatically. Using the affect heuristic in decision making means that the decision is made with reliance on such feelings, expressed in attractiveness ratings in the present study.

Some recent studies of human decision making have applied the Word Association and Imagery Decision analysis method ( WAID) approach to decision making to predict human decisions (Benthin, Slovic, Moran, Severson, Mertz \& Gerrard, 1995). The WAID approach will be presented in more detail later. It uses free associations in the form of words, ideas, images etc having positive or negative attractiveness associated to them. Decision alternatives generate such associations and Slovic, Layman, Kraus, Flynn, Chalmers and Gesell (1991) found that the attractiveness of these associations are significant predictors of future choices (Benthin, Slovic, Moran, Severson, Mertz \& Gerrard, 1995; Peters \& Slovic, 1996). Recently, Loewenstein, 
Weber, Hsee and Welch (2001) contributed an important overview of the role played by affect in human decision making.

\section{Differentiation and Consolidation Theory}

Even though most decisions are fast and requiring little or no conscious attention, there are decision problems that cannot be readily solved in such quick processes. Diff Con models the more elaborate processes needed in such situations. Diff Con includes quicker processes like those treated above as sub-processes of the more elaborate processes elicited in difficult decision situations. Furthermore, Differentiation and Consolidation Theory treats both pre- and post decision processes in a process approach to human decision making (Svenson, 1992, 1996, 2002).

Differentiation is the process in which a preliminarily chosen alternative is separated from its competitors. The differentiation process may involve quick holistic decisions as a result of an application of the affect heuristic. Differentiation also consists of applications of different decision rules, restructuring of the decision maker's representation of the different alternatives, and decision problem restructuring that can generate new alternatives. A necessary condition for differentiation before a decision and consolidation after a decision is that the decision maker is personally involved in the decision. If the decision maker is not sufficiently involved, there will be no strong incentive to drive differentiation and post decision consolidation (Svenson, 2002).

The present contribution will focus on post decision processes. But, pre decision processes of Diff Con will be presented in detail because they closely correspond to the consolidation processes active after a decision. According to Diff Con theory, the goal of a decision process is to find or create a sufficient degree of differentiation between a chosen alternative and its closest competitor, to enable a choice. It is not enough to select the best option. This is both because of cognitive reasons (the chosen alternative should stand out as a "gestalt" or unit against the "background"), and because a sufficiently superior alternative makes the decision less vulnerable to changes of the decision maker's mind, to poor outcomes and post decision regret. After a decision, consolidation processes continue supporting the decision so that it remains or increases in differentiation from its competitors.

Diff Con theory does not require decision alternatives to be represented by aspects from the same set of attributes for all participants and alternatives. Diff Con theory represents decision alternatives through aspects on attributes ordered according to their importance for a decision (Svenson, 1992, 1996). This is why Diff Con can be readily applied to WAID data. The content or "label" of the most important attribute may vary across participants. To exemplify, one participant may consider "salary" as the most important attribute and another participant "work hours" as the most important attribute. In Diff Con theory the ratings from these two participants on their most important attributes are combined and treated as ratings on the most important attribute. Diff Con theory research has shown that regularities in decision making processes, otherwise hidden, can be found if data are treated in this way rather than according to attribute labels (Svenson, 1996). This is because decision makers tend to process aspects, on what they consider the most important attribute, in the same way irrespective of what characteristics that attribute represents. 
There are four different kinds of differentiation processes in Diff Con theory which can be activated in the process of reaching a decision, namely, holistic, process, structural and problem restructuring processes.

(1) Holistic differentiation is a quick nonanalytic process, which often involves subprocesses that are not conscious to the decision maker him or her self. In such decisions, heavily emotion/affect-laden images and associations can be strongly related to a choice (Benthin et al., 1995; Slovic, 2001). These associations may be easy to report or they may be less available for conscious reports. Emotion/affect may also be directly evoked by an alternative as a whole (Slovic, Finucane, Peters \& MacGregor, 2001) without specific conscious reference to aspects characterizing the alternative. Thus, an alternative may trigger an immediate decision without the decision maker being aware of the affective and/or cognitive rationales behind the decision. This kind of preliminary or final differentiation includes Damasio's (1994) somatic marker hypothesis.

(2) Process differentiation involves the processing of available information using one or more decision rules (Beach, 1990; Svenson, 1979). To exemplify with the use of a conjunctive rule, this rule implies the setting of a criterion level on one or more attributes (e.g., price) and going through the available alternatives, rejecting those who fail to pass the criterion level.

(3) Structural differentiation includes three kinds of differentiation, (a) attractiveness differentiation, (b) facts differentiation and (c) attribute importance differentiation. This is the kind of differentiation that will be in focus in the present study.

Attractiveness differentiation means that, in order to achieve a sufficiently superior alternative, the attractiveness of the decision alternatives are gradually changed in support of a preliminary chosen alternative. To exemplify, the perceived beauty of an expensive carpet may be gradually improving in an attractiveness restructuring process until the decision to buy the object becomes possible. Different aspects (images or scenarios) may also appear during the decision process to support a preliminary preferred alternative. Correspondingly, the same process can be used to support a final choice in the post decision stages. Facts restructuring concerns the change of representations of facts to support a decision alternative. For example, when asked about the price of the earlier mentioned carpet, a decision maker can produce a lower price or round off downwards. The alternative is now represented as more beautiful and less expensive than earlier in the decision process. Finally, attribute importance structuring means that aspects supporting the chosen alternative are given increased importance.

(4) Problem restructuring is another type of differentiation, which means that new decision alternatives are created in processes also involving problem solving. Here, the set of given decision alternatives is not accepted as such but new options are created.

Diff Con theory is related to the classic cognitive dissonance approach (Festinger, 1957,1964), but differs from it in several ways. Among the differences are the representation of decision alternatives by aspects on attributes in Diff Con. Classical dissonance theory used holistic evaluations (Festinger, 1964) or information in terms of number of pros and cons relative to an 
alternative (Frey, 1981,1986). The importance or weight of each aspect is explicitly included in Diff Con theory and this has no correspondence in most cognitive dissonance approaches. The goal of the decision process is to create and maintain a sufficiently superior alternative in Diff Con. In the cognitive dissonance approach the goal is to create and maintain cognitive consistency. These goals may or may not coincide. Diff Con, originating from a decision theoretic approach, treats predecision processes to a greater extent than cognitive dissonance research that originated in social psychology.

Festinger (1964) asserted that the pre decision process is largely impartial and that the (overall) attractiveness of the alternatives do not change significantly. In the same vein, Damasio (1994) gives the impression that he also assumes attractiveness or affective values of somatic markers to be relatively stable during a decision process when they have been learned. However, Diff Con theory assumes exactly the opposite. Structural differentiation is the theoretical expression of this assumption. Other researchers in the cognitive dissonance tradition have given up Festinger's assumption about impartial pre decision information processing (Janis \& Mann, 1977). Diff Con theory explicitly presents different decision rules for processing the information in conjunction with the restructuring processes. The restructuring processes are always performed towards greater differentiation or consolidation governed by one or more decision rules that are applied. By way of contrast, most cognitive dissonance approaches have very few assumptions about decision rules (but see Larrick, 1993).

Within and outside the decision theoretic tradition, similar ideas about "biased" information processing before a decision have been given many names, such as, value as a determiner of subjective probability (Slovic, 1966), selective exposure to information (Frey, 1986), wishful thinking (e.g., Hogarth, 1987), outcome bias (Cohen \& Wallsten, 1992), desirability bias (Olsen, 1997), value bias (Yates, 1990), dominance structuring (Montgomery, 1983), comparative advantages (Shafir, Simonson \& Tversky, 1993), confirmation bias (Boiney, Kennedy \& Nye, 1997; Russo, Medvec \& Meloy, 1996; Russo, Meloy \& Medvec, 1998; Russo, Meloy \& Wilks, 2000; Schultz-Hardt, Frey \& Lüthgens, 2000), distortion of information (Russo, Meloy \& Medvec, 1998) and constructed preferences (Payne, Bettman and Johnson, 1992; Slovic, 1995). Holyoak, Simon and colleagues (Holyoak \& Simon, 1999; Simon, Pham, Le \& Holyoak, 2001) use the term of increased coherence during the process of making a decision.

As mentioned earlier, Diff Con is a descriptive theory in that it does not primarily aim at predicting which alternative a decision maker will chose, but instead it aims at studying how the decision process will proceed. By way of contrast, the WAID approach has the primary purpose

of predicting which alternative a decision maker will prefer. As mentioned earlier, WAID will be used to describe decision processes in terms of differentiation and consolidation in the present context.

\section{WAID: Word Association and Imagery Decision analysis approach to decision making}

The present study investigates decision making using the technique of free associations to decision alternatives before and after a decision. As mentioned above, these associations are assumed to have affective components forming their positive or negative attractiveness values according to Damasio's (1994) somatic-marker hypothesis, which he presents in the following 
way: "Somatic markers are special instances of feelings generated from secondary emotions. Those emotions and feelings have been connected, by learning, to predicted future outcomes of

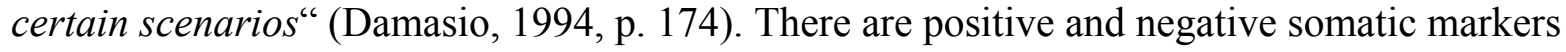
corresponding to the affective reactions associated to decision alternatives

Damasio (1994) exemplifies a renewed interest in affect and emotion including links to neuroscience. He argues that thought is made largely from perceptual and symbolic representations which he calls images. As mentioned above these images are linked to somatic markers. The somatic markers elicit positive and negative feelings that are linked directly or indirectly to bodily states. Negative markers signal alarm and positive markers lead the way forward in a dynamic decision process. In congruence with this, Slovic and colleagues have found strong relationships between imagery and decision making (Benthin, Slovic, Moran, Severson, Mertz \& Gerrard, 1995; Peters \& Slovic, 1996) using the WAID method for eliciting and evaluating the associations.

Slovic, Layman, Kraus, Flynn, Chalmers and Gesell (1991) found how affects (measured by attractiveness ratings) coupled with associations to a stimulus were related to preferences. In their investigations participants were asked to give continued associations (verbal imagery) to a stimulus word (e.g., nuclear power, Nevada). That is, any image or thought (e.g., efficient, dangerous, nice, beautiful) that came to a participant's mind should be said out loud to the investigator. After these free associations had been given, each participant rated the affective quality of his or her own associations on a scale from extremely negative to extremely positive. The affective qualities of the associations obtained in this application of the WAID approach can be used to predict preference and choice.

The WAID approach is in line with Zajonc's view of decision making. He argued that all perceptions contain some affective or emotional component. Furthermore, he stated that emotion and affect are faster than cognitive processes. But cognitive processes can be used to justify decisions based on affective and emotional reactions (Zajonc, 1980). Other researchers who have done interesting work on affect and decision making include Epstein (1994), Isen (1993), Johnson and Tversky (1983), Janis and Mann (1977), Kahneman and Snell (1990), Mellers, Schwartz, Ho and Ritov (1996), Mellers (2000), Loewenstein (1996), Rozin, Haidt and McCauley (1993) and Wilson et al. (1993).

Associations or images were elicited using a version of continued associations (Szalay \& Deese, 1978) in the present study. The associations can be elicited in phone interviews, field studies or in a laboratory setting. The researcher instructs the participant that "...I am interested in the first (N) thoughts that come to mind when you hear the (target word: object, person, activity etc.). " Participants are instructed to always go back to the target word after an association, in order not to produce a chain of associations away from the target via new associations. Following the elicitation of associations, the participants are asked to rate their own associations on an affect scale ranging from positive through neutral to negative. In the following, attractiveness will be used with the same meaning as affect.

If the associations generated by applying the WAID approach can be used in the Diff Con theory framework, the following prediction can be made. The attractiveness advantage of the chosen 
alternative (measured on the affect/attractiveness ratings) compared to the non-chosen alternative will be greater when a decision has been made than it was before. In contrast to earlier Diff Con research, a between groups design will be used instead of a design with repeated measures, which has been used exclusively in the past.

\section{Study 1}

\section{Participants}

A total of 201 participants participated in the study. They were recruited through an advertisement in a University of Oregon student newspaper and they were paid for participating.

\section{Materials and procedure}

The participants were presented two cities (San Francisco and San Diego) one at a time as possible vacation destinations. The instructions read as follows.

"..this study involves word association. For example, when the word "baseball" is mentioned, you might think of the World Series, the Florida Marlins, summertime, or even hot dogs as associations to baseball. Suppose you are thinking of going for a vacation. With this in mind we want you to give a number of associations or images that come to your mind when you think of a city to go to for a vacation. It is important that you read the name of the city before giving each association. This is because we want every association to be triggered by thinking about the city. Start with the association that comes first to your mind, and so on. If you really cannot think of any more associations, please go to the next section in the questionnaire (even if some of the association lines have not been completed). "

There was always space for 8 different associations on the response sheet. On each side of the line for writing down an association, there were two empty spaces, which the participants were asked to leave blank while they were associating and writing down their associations. After having associated to both cities, the participants were again asked to go back to the earlier responses and instructed in the following way.

“ 1 . Now we want you to go back to your earlier associations and rate them from very negative (3 ) to neutral $(0)$ to very positive $(+3)$. See the rating scale below. You should write your rating in column 1 (in front of your association). So for example, if you have written "happy" as an association you would probably give that association a high positive rating. Start with the first city and then go on to the second one. When you have finished, come back here and proceed to the following question on this page (marked 2).“

After the participants had rated the associations, the instruction was the following.

“2. We now want you to indicate how important you think each association is when deciding how attractive a city is for vacation. This will be done through rank ordering the associations and writing " 1 " for the most important association, " 2 " for the next association in importance, and so on. Enter these rankings in column 2 (after your association). Start by picking out the most 
important association and continue with the rest for one city first and then go on to the next city and do a separate ranking for that city."

Half of the participants were asked first to make the decision of which city (San Diego or San Francisco) they would prefer to go to for a vacation, and then they were asked to associate and make the judgments. The other half of the participants made the associations and judgments first and asked to make their choices as the last part of the experiment. The order between the cities was balanced so that in each group half of the participants rated San Diego first and the others San Francisco first.

The data were collected in group settings and the experiment was preceded and followed by questionnaires belonging to other studies.

\section{Results}

\section{Choices}

Of those who made the decision first and gave the associations last, 32 participants preferred San Diego and 67 San Francisco. The corresponding numbers for participants who made the associations first and the decision last were, 37 for San Diego and 65 for San Francisco. Thus, there was no significant difference between the two conditions in terms of which city was preferred.

\section{Associations}

There was no significant difference between the total numbers of associations given in the association last - decision first and association first - decision last conditions. In the same way, there was no significant difference in numbers of associations given by decision makers who preferred San Francisco and by those who preferred San Diego. San Francisco generated more associations (1477) than San Diego (1257). Up to three associations were given to San Diego and up to five to San Francisco by almost everybody. About $47 \%$ of the participants generated the maximum of 8 associations to San Diego and about $70 \%$ gave 8 associations to San Francisco.

In all, 523 of the 2734 associations (19\%) were neutral, that is, rated zero on the scale of attractiveness. Neutral associations were equally prevalent in the decision last (259 associations) and decision first (264 associations) conditions. Thus, a significant minority of the associations were neutral and the majority of the associations (81\%) were attractiveness laden. The nonchosen alternative had more neutral associations (296) than the chosen alternative (227).

Figure 1 in here

\section{Advantage of chosen over non-chosen alternative for decision first and decision-last conditions}

In Figure 1, the attractiveness advantage of the chosen alternative was plotted over attributes sorted in order of importance. It is clear that for San Francisco choices the decision first 
condition shows systematically greater advantages for the chosen alternative across all attributes. In the San Diego choices this is true only for the five most important attributes.

The results show that when the decision was made first (SD_F and SF_F in Figure 1), the advantage of the chosen over the non-chosen alternative was statistically significant on the most important attributes through rank $4(\mathrm{p}<0.01)$. When the corresponding advantages were computed before a decision had been made (SD_L and SF_L), the overall mean advantage was smaller.

Making a decision increased the average attractiveness advantage (over attributes and participants $)$ of the chosen alternative from 0.38 to $0.76(t=2.26 \mathrm{p}=0.012$ one tailed, $\mathrm{df}=174)$. This confirms, the prediction from Diff Con theory that attractiveness restructuring leads to a change of attractiveness structure giving greater advantage for the chosen alternative after a decision has been made

\section{Conclusions}

The results of the first study show that associations and the attractiveness values given to the associations can be used in a Diff Con framework. A significant number of associations were neutral but the majority of the associations were either positive or negative. The neutral ratings of associations show that not all associations carry affective loadings.

When a decision was made the attractiveness advantage of the chosen alternative over the nonchosen alternative was greater than when no explicit decision had been made indicating a post decision consolidation process. This confirms the prediction made and shows that quick associations and their attractiveness ratings can be used in a Diff Con framework.

Emotional affect can be elicited as a holistic reaction to a real or imagined stimulus. This kind of reaction was not asked for in Study 1, but it is assumed to be a powerful predictor of choice (Damasio, 1994). Therefore, initial emotional affective reactions will be collected in Study 2. However, when a decision maker has rated his or her holistic emotional affective reactions to a pair of alternatives, she or he has already reacted in a way that is similar to having made an implicit preliminary decision. For decision makers who follow their first emotional/holistic affective impressions the differentiation can be finished very quickly. Therefore, associations and ratings given after the initial affective ratings but before the formal decision in Study 2 would reflect a later stage of the differentiation process than the pre-decision stage in Study 1. From this follows that the advantage difference between the decision first and decision last conditions should be smaller in Study 2 than in Study 1.

An attractiveness rating of an association to an alternative may be decomposed into emotional/affective and cognitive/rational value components (e.g., Abelson, Kinder, Peters \& Fiske, 1982; Svenson, 2002). If the attractiveness ratings of the associations reflect primarily emotional affective responses as asserted in Study 1 and by Slovic and coworkers (Benthin, Slovic, Moran, Severson, Mertz \& Gerrard, 1995), the emotion/affect component of the attractiveness ratings should be dominating and the cognitive/rational value component should play a minor role. After having produced the associations and the attractiveness ratings, the 
participants will therefore be asked to decompose the attractiveness ratings into an "emotional/affect" component and a "cognitive/rational value" component in Study 2.

\section{Study 2}

One purpose of Study 2 was to replicate the consolidation effect found in Study 1. Because of the initial holistic affect/emotion ratings the effect was expected to be weaker in Study 2 compared to the effect in Study 1. Another purpose was to explore if an attractiveness rating can be decomposed in a meaningful way into an affective/emotion and a rational/choice component through simple instructions to the participants. Assuming that quick associations would be more emotional than rational, the emotion affect component would be stronger than the rational value component. The design in Study 2 was similar to the design used in Study 1 with a few significant differences.

\section{Method}

\section{Subjects}

A total of 183 students at Stockholm University, Sweden participated in the study. They were recruited among psychology students who could participate in partial fulfillment of a course requirement.

\section{Materials}

The participants were presented two European cities, Paris and Rome for a vacation choice in the same manner as in Study 1. The instruction to the participants was the same as the one used in Study 1, but with minor adaptations of, for example, baseball (basically unknown in Sweden) to tennis and a few other minor linguistic changes to fit the Swedish participants.

Before the experiment started the participants were asked to rate their spontaneous holistic impression of the two cities.

"First of all we want to have your spontaneous holistic reactions to each of two potential vacation cities, Rome and Paris, in terms of emotional feelings on a scale from very negative (-3) to very positive $(+3)$.

My spontaneous holistic/overall emotional reaction to Paris is: ..”

After this, the procedure was the same as in Study 1 until a new set of ratings followed. The additional ratings concerned how much each of the original associations could be related to an emotional/affective evaluation and how much it could be related to a (cognitive) rational evaluation. The instruction included the following (in translation from Swedish).

"In particular, we want to know how strong the emotional/affect component was in an association. In the same way we want to know the strength of the evaluative rational component.".."If, for example, you have rated the attractiveness to -3 , ...the emotion/affect 
component can be -3 and the rational component $+1 . "$...."You should not feel that the (earlier) attractiveness rating should be some kind of mean of the emotion/affect and rationality ratings."..

On the response sheet, the participants were instructed to go back to their earlier associations first and write down the words for the association again on the new page and then write the earlier attractiveness rating in front of each association. Finally, the participants were asked to rate the emotion/affect strength related to that association and the rational evaluation strength related to the association. The ratings were given as numbers from -3 (strongest negative evaluation) over 0 (no strength) to +3 (strongest positive evaluation).

\section{Design}

The design was the same as in Study 1 with 91 participants making the decision first and 92 making the decision last. The order between the cities was balanced so that in each group half of the participants rated Paris first and half Rome first. The data were collected in group settings. Each session lasted for about an hour.

\section{Results}

\section{Choices}

A majority of the participants preferred Rome. Of those who made the decision first, 57 decided to go to Rome and 34 to Paris. The corresponding numbers for decision last were 54 and 38 indicating no significant difference between the two conditions.

\section{Associations}

All subjects (183) gave at least 3 associations for each alternative. Paris elicited four associations or more from 180 participants and Rome did the same from 178 participants. In all, 1305 associations were produced in response to Paris and 1243 associations to Rome. This corresponds to an average of 7.1 associations to Paris and 6.8 associations to Rome respectively. Paris was given all 8 associations by $62 \%$ of the participants and Rome 8 associations by $52 \%$ of the participants. As in the earlier study a significant minority of the associations were neutral.

\section{Consolidation: affect/attractiveness}

With regard to the mean rated attractiveness values, the advantage of the chosen over the nonchosen alternative was significant on the $5 \%$ or $1 \%$ levels for 6 of the 8 attributes in the decision first condition. This was also the case for 6 of the attributes in the decision last condition. In the decision first condition, the mean advantage over attributes and participants of the chosen alternative compared to its competitor, 0.66 was also significant as well as the advantage, 0.53 in the decision last condition ( $\mathrm{t}$-tests, $\mathrm{p}<0.01$ ). Thus, Study 2 showed an increase in advantage (0.13) indicating consolidation after the decision had been made just as in Study 1. In line with our expectations, the increase in mean advantage was smaller than in Study 1 and it did not reach statistical significance. Figure 2 illustrates the results of Study 1 and Study 2. 


\section{Attractiveness, affect and value relationships}

The interrelationships between mean attractiveness and (1) holistic/overall emotional reactions, (2) mean cognitive/rational value ratings and (3) mean emotion/affect ratings were described by the correlations in Table 1. First, the correlations between mean attractiveness ratings and mean emotion/affect ratings are always greater than the correlations between the attractiveness ratings and the mean cognitive/rational value ratings. This shows that that the emotion affect component was more strongly related to attractiveness than the rational value component.

Table 1 in here

The immediate overall emotional reaction also correlates significantly with the mean attractiveness ratings. When the decision was made first, the correlation between attractiveness and cognitive/rational value ratings were smaller for the chosen alternative than when the decision was made last $(\mathrm{p}<0.01)$. The correlations between the holistic/overall emotional reactions and the mean emotion/affect ratings were all significant $(\mathrm{p}<0.001)$ and were in the same range as the correlations between the holistic ratings and mean attractiveness (not shown in Table 1).

Both Paris and Rome were very positive vacation alternatives and elicited many maximally positive holistic affect/emotion ratings and many ties. There were $42 \%$ ties in the decision last condition and $31 \%$ in the decision last condition. When the holistic ratings differed for the two cities Rome was predicted correctly in $100 \%$ and Paris in $73 \%$ of the cases (the decision last condition). The post dictions (the decision first condition) were 100\% correct for Rome and $81 \%$ correct for Paris.

\section{Differentiation and consolidation: affective/emotion and cognitive/rational components}

The emotion/affect and cognitive/rational judgments were given on the same -3 to +3 scales as all other judgments and were used as indicators of differentiation and consolidation. The emotion/affect judgments indicated significant differentiation and consolidation for each of the 5 most important attributes in the decision first condition. The mean emotion/affect advantage over attributes for the chosen alternative was 0.62 in the decision first condition and statistically significant $(\mathrm{t}=5.04, \mathrm{df}=90, \mathrm{p}<0.001)$. In the decision last condition the advantage was $0.36(\mathrm{t}=$ $2.49, \mathrm{df}=91, \mathrm{p}<0.01)$ and the difference, 0.26 between these advantages was not significant at the $5 \%$ level.

The mean advantage over attributes of the cognitive/rational ratings in the decision first condition (0.12) and in the decision last condition (0.17) were not statistically significant. Thus, the emotion/affect ratings significantly reflected differentiation/consolidation of the chosen alternative, while the advantages found for cognitive/rational judgments did not. However, the emotion/affect component in itself was not as strong an indicator of differentiation and consolidation as the attractiveness judgments indicating that the latter was the best indicator of consolidation. 


\section{Concluding remarks}

The present study has illustrated how free associations can be used in descriptions of decision processes. A significant minority of associations was neutral, which contrasts with the view that all associations have positive or negative affective values. The present contribution was able to show how consolidation of a prior decision was reflected in the affect values of free associations to the decision alternatives. The elicitation of initial holistic affect ratings in Study 2 seemed to trigger an implicit preliminary choice followed by a very quick differentiation process. A methodological extension over earlier Diff Con research was the present between groups design with measures at different stages in the decision process. When attractiveness was decomposed into an affect/emotion and a cognitive/rational component, the affect/emotion ratings correlated more with the affect/attractiveness ratings and described consolidation better than the cognitive/rational component. This illustrates how attractiveness ratings of quick free associations primarily may reflect emotional affective reactions to decision alternatives and not emotion free values.

\section{References}

Abelson, R.P., Kinder, D.R., Peters, M.D. \& Fiske, S. (1982) Affective and semantic components in political person perception. Journal of Personality and Social Psychology, 42, $619-630$.

Benthin, A., Slovic, P., Moran, P., Severson, H., Mertz, C. K \& Gerrard, M. (1995) Adolescent health-threatening and health-enhancing behaviors: A study of word association and imagery. Journal of Adolescent Health, 17, 143 - 152.

Boiney, L.G., Kennedy, J. \& Nye, P. (1997) Instrumental bias in motivated reasoning: More when more is needed. Organizational Behavior and Human Decision Processes, $72,1-24$.

Beach, L.R. (1990) Image theory: Decision making in personal and organizational contexts. Chichester: Wiley.

Cohen, B. \& Wallsten, T. S. (1992) The effect of consistent outcome value and judgments and decision maiking given linguistic probabilities. Journal of Behavioral Decision Making, 5, 53 72.

Damasio, A., R. (1994) Descarte's error: Emotions, reason and the human mind. New York: Avon.

Epstein, S. (1994) Integration of the cognitive and psychodynamic unconscious. American Psychologist, 49, $709-724$.

Festinger, L., (1957). A theory of cognitive dissonance. Stanford, CA: Stanford University Press.

Festinger, L. (1964) Conflicts, decision and dissonance. Stanford CA: Stanford University Press. 
Frey, D. (1981) Postdecisional preference for decision-relevant information as a function of its source and the degree of familiarity with its information. Journal of Experimental Social Psychology, 17, 51-67.

Frey, D. (1986) Recent research on selective exposure to information. Advances in experimental social psychology, 19, 41-80.

Hogarth, R. M.(1987) Judgment and choice. New York: Wiley.

Holyoak, K.J. \& Simon, D. (1999) Bidirectional reasoning in decision making by constrained satisfaction. Journal of Experimental Psychology: General, 128, 3 - 31.

Isen, A. M. (1993) Positive affect and decision making. In M. Lewis \& J. M. Haviland (Eds.) Handbook of emotions, New Yor The Guilford Press, pp 261 - 277).

Janis, I.L. \& Mann, L. (1977) Decision making: Apsychological analysis of conflict, choice and committment.New York: Free Press.

Johnson, E. J. \& Tversky, A. (1983) Affect, generalization and the perception of risk. Journal of Personality and Social Psychology, 45, $20-31$.

Kahneman, D. \& Snell, J. (1992) Predicting a changing taste: Do people know what they will like? Journal of Behavioral Decision Making, 5, 187-200.

Larrick,R.P. (1993) Motivational factors in decision theories. The role of self-protection. Psychological Bulletin, 113, 440 - 450.

Loewenstein, G. (1996) Out of control: Visceral influences on behavior. Organizational Behavior and Human Decision Processes, 65, 272 - 292.

Loewenstein, G., Weber, E. U., Hsee, C. \& Welch, N. (2001) Risk as feelings. Psychological Bulletin, 127, $267-286$.

Mellers, B. A., Schwartz, A., Ho, K. \& Ritov, I. (1999) Elation and disappointment: Emotional responses to risky options. Journal of Experimental Psychology: General, 128, 332 - 345.

Mellers, B. A., (2000) Choice and the realtive pleasure of consequences. Psychological Bulletin, 126, $910-922$.

Montgomery, H. (1983) Decision rules and the search for a dominance structure: Towards a process model of decision making. In P.C. Humphreys, O. Svenson, \& A. Vari (Eds.) Analyzing and aiding decision processes (pp. 343-369) Amsterdam: North-Holland.

Mowrer, O.H. (1960a) Learning theory and behavior. New York: Wiley. 
Mowrer, O.H. (1960b) Learning theory and the symbolic processes. New York: Wiley.

Olsen, R.,A. (1997) Desirability bias among professional investment managers: Some evidence from experts. Journal of Behavioral Decision Making, 10, 65 - 72.

Payne, J.W., Bettman, J.R. \& Johnson, E.J. (1992). Behavioral decision research: A constructive processing perspective. Annual Review of Psychology, 43, 87-131.

Peters, E. \& Slovic, P. (1996) The role of affect and worldviews as orienting dispositions in the perception and acceptance of nuclear power. Journal of Applied Social Psychology, $26,1427-1453$.

Rozin, P. Haidt, J. \& McCauley, C. R. (1993) Disgust. In M. Lewis \& J. M. Haviland (Eds.) Handbook of emotions New York: Guilford pp 575-594.

Russo, J. E., Medvec, V.H. \& Meloy, M.G. (1996) The distortion of information during decisions. Organizational Behavior and Human Decision Processes, 66, 102 - 110.

Russo, J. E., Meloy, M. G. \& Medvec, V. H. (1998) The distortion of product information during brand choice. Manuscript.

Russo, J.E., Meloy, M. G. \& Wilks, T. J. (2000) Predecisional distortion of infoormation by auditors and salespersons. Management Science, 46, 13 - 27.

Schultz-Hardt, S., Frey, D. \& Lüthgens, C. (2000) Biased information search in group decision making. Journal of Personality and Social Psychology, 78, 655 -669.

Shafir, E., Simonson, I. \& Tversky, A. (1993) Reason-based choice. Cognition, 49, 11 36.

Simon, D., Pham, L.B.,Le,Q.A. \& Holyoak, K.J. (2001) The emergence of coherence over the course of decision making. Journal of Experimental Psychology: Learning, Memory, and Cognition, 27, 1250 -1260.

Slovic, P. (1966) Value as a determiner of participantive probability. IEEE Transactions on Human Factors in Electronics, Vol. HFE-7 (pp. 22-28.

Slovic, P. (1995) The construction of preference. American Psychologist, 50, $364-371$.

Slovic, P. (2001) Rational actors and rational fools: The influence of affect on judgment and decision making. Paper prepared for Symposium "Rational actors or rational fools? The implications of psychology for products liability". Roger Williams University, Bristol Rhode Island April 21, 2000. 
Slovic, P., Finucane, M., Peters, E. \& MacGregor, D., G. (2001) The affect heuristic. In T. Gilovich, D. Griffin \& D. Kahneman (Eds.) Intuitive judgment: Heuristics and biases. Cambridge: Cambridge University Press, in preparation.

Slovic, P., Layman, M, Kraus, N., Flynn, J., Chalmers, J. \& Gesell, G. (1991) Perceived risk, stigma and potential economic impact of a high-level nuclear waste repository in Nevada. Risk Analysis, 11, 683 - 696.

Slovic, P., Layman, M. Kraus, N. Flynn,, J., Chalmers, J. \& Gesell, G. (1991) Perceived risk, stigma, and potential economic impacts of high level nuclear waste repository in Nevada, Risk Analysis, 11, 683 - 696.

Svenson, O. (1979) Process descriptions of decision making. Organizational Behavior and Human performance, 23, 86-112.

Svenson, O. (1992) Differentiation and consolidation theory of human decision making: A frame of reference for the study of pre- and post decision processes. Acta Psychologica, 80, 143-168.

Svenson, O. (1996) Decision making and the search for psychological regularities: What can be learned from a process perspective? Organizational Behavior and Human Decision Processes, $65,252-267$.

Svenson, O. (2002) Values and affect in human decision making: A Differentiation and Consolidation Theory perspective. In S. L. Schneider and J. Shanteau (Eds.) Emerging perspectives on judgment and decision making research in press.

Szalay, L. B. \& Deese, J. (1978) Participantive meaning and culture: An assessment through word associations. Hillsdale, NJ: Lawrence-Erlbaum.

Wilson, T. D., Lisle, D. J., Schooler, J. W., Hodges, S. D., Klaaren, K.J. \& LaFleur, S. J. (1993) Introspecting about reasons can reduce post-choice satifaction. Personality and Social Psychology Bulletin, 19(3), 331 - 339.

Yates, F. (1990) Judgment and decision making. Englewood Cliffs, NJ: Prentice Hall.

Zajonc, R.B. (1980) Feelings and thinking: Preferences need no inferences. American Psychologist, 35, 151-175. 
Figure captions

Figure 1 Advantage of chosen over non-chosen alternative for San Diego and San Francisco choices. Filled symbols indicate decision first and associations last. Open symbols indicate that the associations were produced first and the decision made last. The $\mathrm{x}$ - axis indicates associations (attributes) rank ordered in importance with 1 for the most important attribute, 2 for the second most important attribute and so on.

Figure 2. Mean advantage of chosen alternative over non-chosen alternative in Study 1 and Study 2. 
Table 1. Average attractiveness ratings correlated with overall emotional reaction to decision alternative, average emotion/affect and cognitive/rational value ratings of associations. European cities study.

\begin{tabular}{|c|c|c|c|c|}
\hline \multirow{2}{*}{$\begin{array}{l}\text { Average } \\
\text { attractiveness } \\
\text { correlated with }\end{array}$} & \multicolumn{2}{|c|}{ Associations first - decision last } & \multicolumn{2}{|c|}{ Associations last - decision first } \\
\hline & $\begin{array}{l}\text { Chosen } \\
\text { alternative }\end{array}$ & $\begin{array}{l}\text { Non-chosen } \\
\text { alternative }\end{array}$ & $\begin{array}{l}\text { Chosen } \\
\text { alternative }\end{array}$ & $\begin{array}{l}\text { Non-chosen } \\
\text { alternative }\end{array}$ \\
\hline $\begin{array}{l}\text { Overall } \\
\text { emotional } \\
\text { reaction }\end{array}$ & $.68 * * *$ & $.69 * * *$ & $.36 * * *$ & $.59 * * *$ \\
\hline $\begin{array}{l}\text { Average } \\
\text { cognitive/rational } \\
\text { value ratings }\end{array}$ & $.57 * * *$ & $.50 * * *$ & .22 & $.49 * * *$ \\
\hline $\begin{array}{l}\text { Average } \\
\text { emotion/affect } \\
\text { ratings }\end{array}$ & $.84 * * *$ & $.68 * * *$ & $.81 * * *$ & $.79 * * *$ \\
\hline
\end{tabular}

Note - significant alpha $*=0.05 * * *=0.001$ 


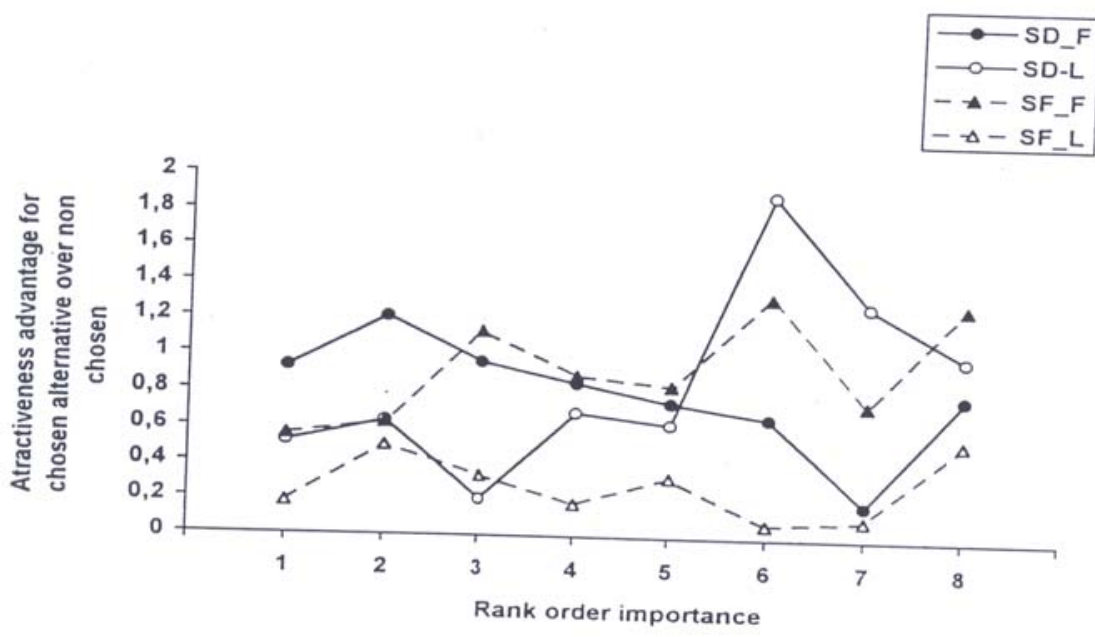

Figure 1. 


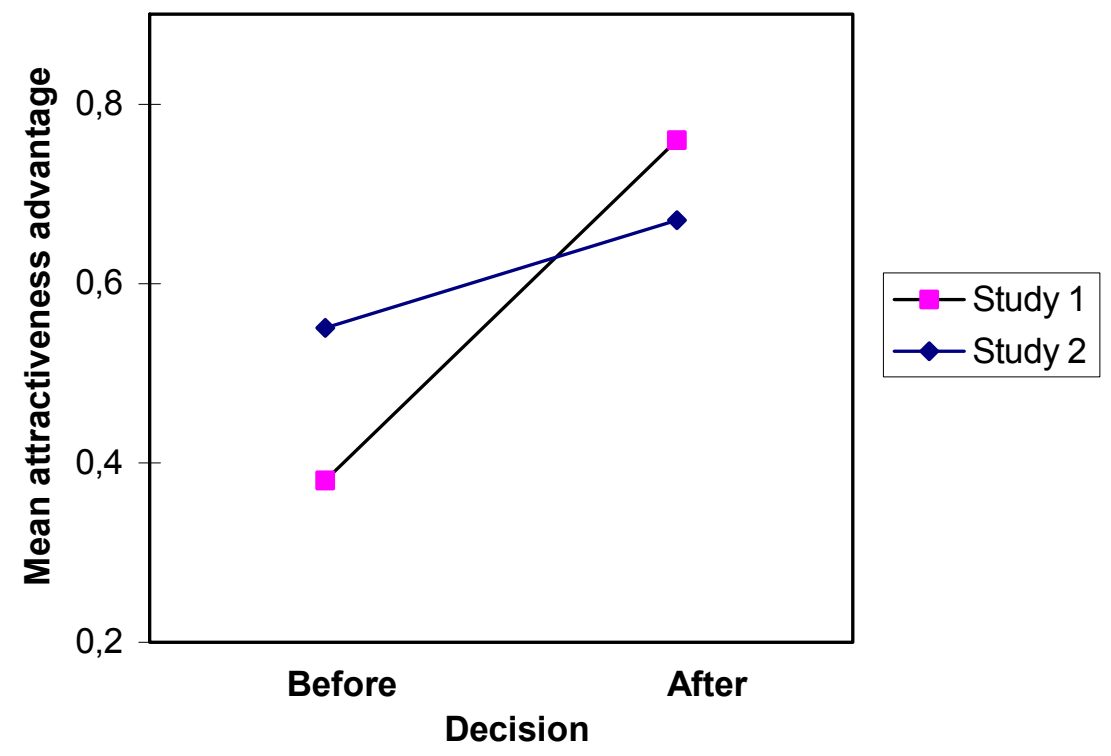

Figure 2. 